\title{
Monopoly Characteristics and Policy Analysis of China's Online Retail Market
}

\author{
Boda Li \\ Tianjin Heping District Yunzhou Course Training School, China \\ xancyy@outlook.com
}

\begin{abstract}
The network retail industry has been in a highly centralized pattern. According to the relevant concepts in the traditional industrial organization theory, this highly concentrated market needs regulation. Behind the rapid development of industry is the hidden worry that is constantly exposed. In 2011, Taobao announced a substantial increase in annual fees and software service fees, which caused conflicts with small and medium sellers. In the price war in Jingdong, it may have been sold at a price lower than the cost. The traditional industrial organization theory usually thinks that the monopoly market structure is not good. Because of its pricing model based on its own marginal cost and marginal income, it will cause welfare losses to consumers, resulting in low market efficiency and unnecessary losses. This paper first expounds the basic connotation and judgment criteria of monopoly, analyzes the monopoly and characteristics of online retail industry in the "Internet +" era, and finally puts forward some governance strategies for the monopoly problems existing in the current online retail industry.
\end{abstract}

Keywords: Online Retailing; Monopoly; Market Efficiency.

\section{Introduction}

Since China Merchants Bank launched online banking services in China in September 1999, online retailing and e-commerce in China have officially started their embryonic stage. Then in 2003, Taobao and Jingdong were established one after another. From 2010, it officially entered a period of rapid development, and the market form gradually turned into oligopoly competition. Different from the traditional industrial monopoly, the monopoly under the Internet not only enables enterprises to control the price changes, but also enables enterprises to obtain countless private information [2]. Through these big data calculations, Internet companies can more accurately extract the most producer surplus from each consumer, which will reduce the production efficiency of the whole industry. Chinese e-commerce companies have mastered the private information of 782 million online shoppers in China, and their security problems are worth studying.

\section{Definition and Judgment Standard of Monopoly}

Monopoly means that an enterprise can be the price maker rather than the receiver in the industry. Therefore, one of the characteristics of monopoly is that it can control the price or quantity of commodities. The types of monopoly market can be subdivided into complete monopoly market, oligopoly market and monopoly competition market. Completely monopolized market basically does not appear in the market where private enterprises compete, which means that an enterprise completely controls the price fluctuation of an entire industry. For some industries which are very important for national construction, they are very suitable for this market form, such as railway industry (China Railway), electric power industry (China Power Grid) and military industry [3]. But usually the main purpose of these industries is not to make as much profit as possible. Establishing enterprises by the state to form a complete monopoly can ensure the safety of the industry and maximize the production efficiency. Oligopoly market is a market state formed by a few enterprises occupying the vast majority of the industry share. Because there are still competitors, oligopolistic enterprises cannot completely control the price changes, but they will have a greater impact on price fluctuations. Monopoly market is a market structure with a large number of enterprises and a small scale, but the products sold are differentiated. 


\section{Monopoly and its Characteristics in the "Internet +" Era}

E-commerce can be divided into many different business models, so it can be subdivided into several different markets. Here, we discuss the most mainstream $\mathrm{C} 2 \mathrm{C}$ and $\mathrm{B} 2 \mathrm{C}$ experience models in China. Taobao's business model is C2C, while Taobao's Tmall Mall and Jingdong's self-operated business model are B2C. This makes Taobao and Jingdong's self-management belong to oligopoly in their $\mathrm{C} 2 \mathrm{C}$ and $\mathrm{B} 2 \mathrm{C}$ online retail markets, but they can be defined as different types - bilateral monopoly and unilateral monopoly.

\subsection{Taobao Monopoly Mode and Loss (C2C Online Retail Market)}

Taobao occupies over $70 \%$ market share in $\mathrm{C} 2 \mathrm{C}$ market, which is defined as oligopoly. Taobao $\mathrm{C} 2 \mathrm{C}$ 's business model makes it necessary to attract buyers and sellers to trade on the platform at the same time, and then it is defined as bilateral monopoly. Therefore, in Taobao's business process, if the buyer or seller is forced to trade on Taobao platform, it will touch the anti-monopoly clause. Taobao's monopoly mode is closely related to its specific business mode, because Taobao can control the seller's market of commodities. Unlike Jingdong's self-management, it sells its own purchased products. In Jingdong's self-operation, only the goods need to be considered, while in Taobao, the credibility of the store needs to be considered first. Because in Taobao, merchants sell to customers, Taobao can control the exposure of each store. Therefore, merchants must pay a drainage fee for Taobao to bring greater sales. As a result, Taobao has a stronger control over the seller's market. However, Taobao has the control over the seller's market, and it can control the buyer's market by using the quantity and pricing of commodities, thus turning into a bilateral monopoly. For example, in April 10, 2021, the General Administration of Market Supervision of China asked Alibaba Group to "choose one from the other" for merchants in the platform, which harmed the interests of merchants and consumers [4]. According to the relevant provisions of the Anti-Monopoly Law, according to 4\% of Ali's sales in 2019, a fine of 18.228 billion yuan was imposed. In this incident, Alibaba used unfair means in the competition, forcing merchants not to sell on any other market platform while selling on Taobao platform, thus being reported as a fine. This fine shows that Alibaba's actions have already caused harm to businesses and this market. If it is not stopped, Taobao will gradually evolve into a complete monopoly market in $\mathrm{C} 2 \mathrm{C}$ market. If this is a completely monopolized market, only one platform can survive and be chosen by the public. From a certain point of view, the platform action can even greatly affect the economy of a market and even the whole industry.

\subsection{Monopoly Mode and Loss in Jingdong (B2C Online Retail Market)}

According to the quarterly monitoring report of B2C market of online retail in China in the first quarter of 2021 released by Analysis, the transaction scale of B2C market of online retail in China in the first quarter of 2021 was RMB 1,601.03 billion. Among them, Tmall and Jingdong account for $63 \%$ and $26.5 \%$ of the market respectively [5]. Therefore, $89.5 \%$ of China's online retail B2C market already occupied by the two platforms can be defined as oligopoly market. That is, a few brands have the vast majority of market share. Jingdong's self-operated B2C business model makes it only need to attract customers in the buyer's market to spend on the platform, and then it is defined as unilateral monopoly. Compared with Taobao, Jingdong is unlikely to touch anti-monopoly clauses under various marketing and publicity strategies to attract consumers. Because consumers are more difficult to manipulate than businesses. It is also difficult for consumers to be forced to spend only on a certain platform.

Jingdong's self-operated B2C mode makes it unable to achieve maximum efficiency (for the whole society) while maximizing its benefits. When prices can be manipulated, monopoly enterprises are more willing to choose higher prices and less sales instead of lower prices and more sales. Because more products mean higher manpower, manufacturing and transportation costs [6]. Although this can maximize the profits of enterprises, it cannot bring more productivity to society to the maximum. If you choose to sell more at a lower price, enterprises will face more costs, but there will also be profits. 
This can drive the development of related industries, such as logistics and manufacturing industries, thus bringing more job opportunities and boosting the overall economic development of the country.

\section{Countermeasures for the Management of Network Monopoly}

Whether Jingdong or Taobao, their markets are close to maturity, especially the C2C model. For today's online shopping platform, regardless of the business model, if the product quality and service pass, the traffic can determine the life and death of a platform [7]. However, as far as the country is concerned, Taobao and Jingdong account for more than $80 \%$ of the total traffic, which can support their monopoly. Therefore, the market form does not have great possibility to become a monopoly competitive market. Completely monopolizing the market is undoubtedly harmful to the country. Therefore, the country should maintain the current market form, but slowly make the traffic ratio between Taobao and Jingdong decrease. Specifically as follows:

\subsection{Lower Barriers to Entry}

When Taobao and Jingdong have already divided most of the traffic, the industry barriers are slowly rising. When most of the traffic in the market is occupied by a few enterprises, enterprises that want to enter this market need to invest a great deal of time and money to obtain traffic, to attract buyers and sellers, thus successfully entering the market and achieving profit. This leads to the increase of monopoly barriers, so that this market can no longer attract new enterprises to enter, and then may lose the vitality and innovation of the market. In order to continuously increase the exposure, the marketing and advertising expenses will also increase, and then the market shape will gradually develop into a complete monopoly. In order to curb this situation, the state can introduce relevant policies to encourage more enterprises to enter the online retail market, to transfer part of the traffic from Taobao and Jingdong, or lower the overall cost of online marketing, to lower industry barriers and attract more new enterprises to start. As long as there are no excessive barriers to entry and a steady stream of new enterprises enter the industry, most of the traffic can no longer be controlled by only a few enterprises. At the same time, the increase of competition has the effect of catfish, which can better stimulate the rapid development of the industry, and consumers have more choices.

\subsection{Information Control}

Internet monopoly is not only the monopoly of price but also the monopoly of information. Nowadays, the traffic is too large and only controlled in one or two enterprises, which also brings information hidden trouble. The hidden dangers of information will be mapped to all industries related to daily life, such as education, medical care, real estate and tourism, etc. The platform gains more profits through big data analysis. The total number of online shoppers in China is 782 million, while Taobao and Jingdong account for over 80\% [8]. They can infer consumers' hobbies, living environment and consumption level by collecting consumers' online shopping data, and then accurately extract as many producers' surplus as possible from each consumer according to local conditions. Once the disclosure of private information occurs, not only consumers' online shopping consumption, but also the price of every consumption of each consumer will be maximized. Merchants earn huge profits. Therefore, on the one hand, the state should strictly control the private information collected by these online platforms to ensure that they are not leaked or capitalized. On the other hand, we should reduce the concentration of market share. Because in the online retail market, market share represents traffic. If the market share concentration is not high, such as monopolizing the competitive market. The overall flow is dispersed to many small enterprises, and an enterprise no longer has enough sample analysis, so it is impossible to get more producer surplus. So naturally, there will be no potential safety hazard of information capitalization.

Data manipulation can ensure the safety of users in the process of network operation, and can effectively prevent private information from being used. The hierarchical information security organization is shown in Figure 1. 


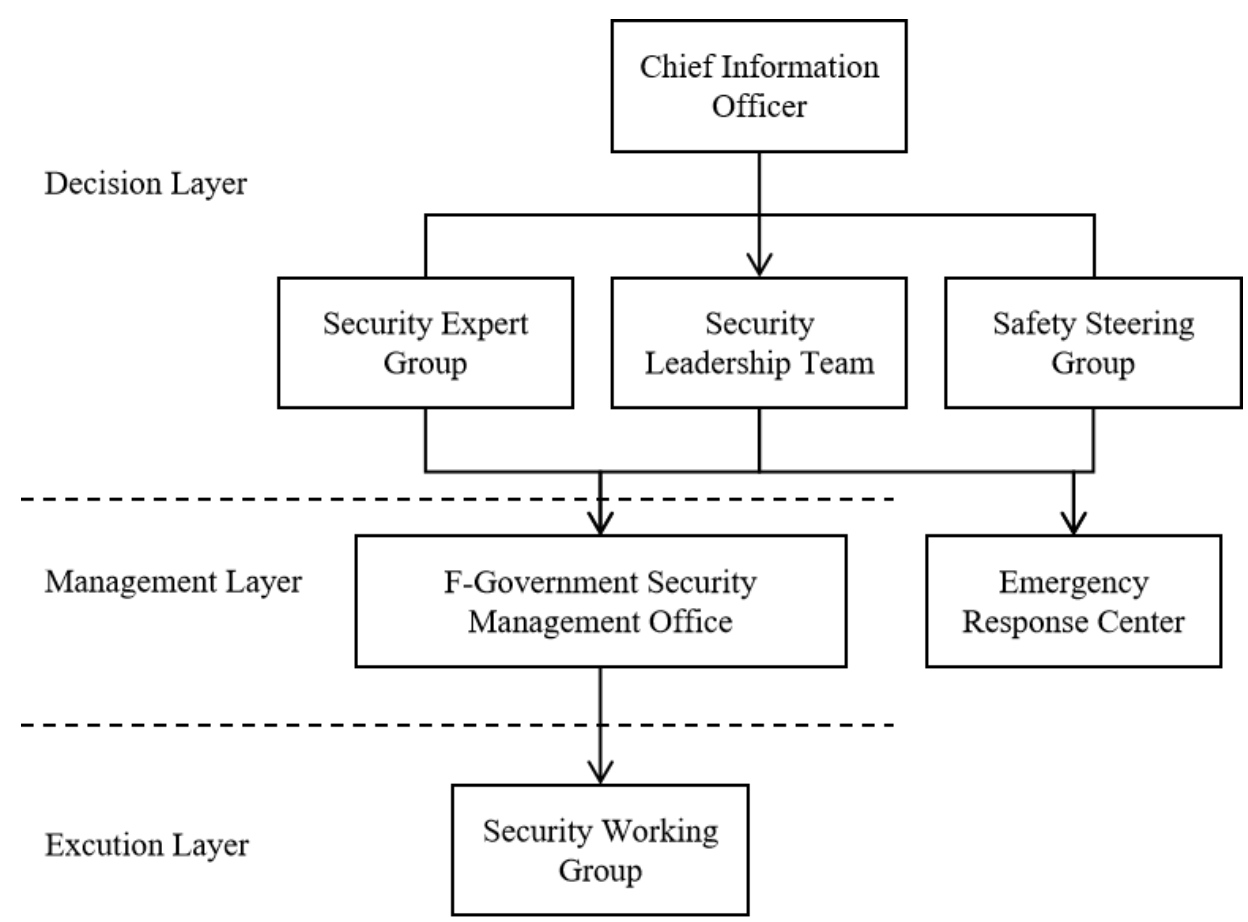

Figure 1. Hierarchical information security organization

\section{Conclusion}

For a long time, compared with the orderly development of traditional physical retail enterprises under market supervision and legal supervision, China's platform-based B2C online retail has many problems, such as the large number of enterprises but the uneven quality, the lack of a clear regulatory body, and the vacancy in the formulation of laws and regulations. For service platforms, it is necessary to monitor the proportion of commission collection and whether they abuse the monopoly position of data. When the transaction volume of service platform accounts for the increasing proportion of total social retail transaction volume, consumers' dependence on the platform will increase continuously, and the welfare reduction caused by consumers giving up trading on the platform and turning to traditional retail will also expand. The supervision of self-operated platforms should focus on monitoring predatory pricing and high price markup. As the self-operated retail platform has the effect that the stronger and the weaker, it is suggested to be cautious about the self-operated online retail platform with strong monopoly power. Internet monopoly is not only the monopoly of price but also the monopoly of information. In the era of big data, data is an important source for enterprises to create value, exert innovation vitality and even compete with each other. Effective supervision should be formed for big data enterprises, to ensure that big data enterprises will not abuse their dominant position in the data field and that public data will not be used for improper channels.

\section{References}

[1] Li Xialin. Analysis on Several Issues Concerning Online Shopping Price Supervision [J]. China Price Supervision and Antitrust, 2016 (7):53-56.

[2] Fang Ruoyi. Analysis of price competition strategy of duopoly online retailers [J]. Business Stories, 2019 (05): 96-98.

[3] Li Zenglu, Nie Jiajia, Feng Lin. Product pricing and advertising strategy analysis considering the limited IT service capabilities of online retailers [J]. Industrial Engineering, 2018, 114(02): 30-40.

[4] Wang Yong, Qi Haifeng. Analysis of the relationship between online retail and traditional retail in urban development [J]. Business Economics Research, 2018, 759(20):7-10.

[5] Lu Yuduo. Research on service pricing of cross-border e-commerce platforms under monopoly market structure [J]. Technology and Management, 2016(3): 32-39. 
[6] Zhong Shenggen. Research on the Impact of Cross-border E-commerce on Trade Intermediaries [J]. Business Economics Research, 2019, 765(02):128-130.

[7] Pei Xueliang, Guo Jianing, Lu Fanying, et al. Exploration of the relationship between competitive priority elements of online retail organizations [J]. Business Times, 2020, 000(011): 97-100.

[8] Zhang Daorun, Jiang Huiyu. A reasonable definition of the amount of data in the merger of e-commerce enterprises [J]. China Cooperative Economy, 2019, 385(06):50-52. 